УДК: $316.776 .3: 378.4$

$10.17213 / 2075-2067-2021-1-45-52$

\title{
ЖИЗНЕННЫЕ ШАНСЫ КАРЬЕРНОГО РОСТА МОЛОДЕЖИ В НОВОЙ СОЦИАЛЬНОЙ РЕАЛЬНОСТИ В КОНТЕКСТЕ ДИФФЕРЕНЦИРУЮЩИХ РАЗЛИЧИЙ
}

\author{
(C) 2021 г. Н. С. Иваненко
}

\section{Южнно-Российский государственный политехнический университет (НПИ) имени М. И. Платова, г. Новочеркасск, Россия}

Цель исследования заключается в описании сочиоструктурных и сочиокультурных факторов, влияющих на жизненные шансы и карьерный рост студенческой молодежи в условиях изменяющейся социальной реальности, растущчего разнообразия неравенств и новых тенденций функциионирования рынка труда и занятости.

Методологическая база исследования опирается на теорию соииальной стратификации П. Сорокина о критериях сочиальных различий и сочиальной мобильности, о специфике функциональной роли института образования как канала селекциии и вертикальной мобильности молодежи. Жизненное самоопределение молодежи рассмотрено в контексте механизмов сочиокультурной саморегулящии поведения Ю. А. Зубок. Признаки процессов прекаризации в молодежной среде описаны на основе теоретических взглядов Ж. Т. Тощенко.

Результаты исследования дают основания предположить, что в новой социальной реальности продолжаются процессы дифференциачии и иерархизачии сочииального положения студенческой молодежи, причем интенсивность этих прочессов связана с территориальными и региональными особенностями, с готовностью выпускников продолжить профессиональную карьеру по полученной в вузе специальности или найти на рынке занятости нишу, обеспечивающую возрастающие материальные потребности и достойный уровень жизни.

Дальнейшее исследование будет нацелено на изучение влияния социального, регионального и культурного неравенства на осуществление жизненных устремлений молодежи, а также на сочиальные последствия прочессов цุифровизации, внедрения информационных технологий на уровень и качество жизни молодежи.

Ключевые слова: стратификациионные различия; жизненные шансы; прекаризаџия; рынок труда; занятость; карьера; карьерный рост.

\section{LIFE CHANCES OF CAREER GROWTH OF YOUNG PEOPLE IN THE NEW SOCIAL REALITY IN THE CONTEXT OF DIFFERENTIATING DIFFERENCES}

\section{(C) $2021 \quad$ N. S. Ivanenko}

\section{Platov South Russian State Polytechnic University (NPI), Novocherkassk, Russia}

The purpose of the study is to describe the socio-structural and socio-cultural factors that affect the life chances and career growth of students in the changing social reality, the growing diversity of inequalities and new trends in the functioning of the labor market and employment. 
The methodological basis of the research is based on the theory of social stratification of P. Sorokin on the criteria of social differences and social mobility, on the specifics of the functional role of the institute of education as a channel of selection and vertical mobility of young people. Vital self-determination of young people is considered in the context of the mechanisms of sociocultural self-regulation of behavior by Yu. A. Zubok. Signs of precarization processes in the youth environment are described on the basis of the theoretical views of Zh. T. Toshchenko.

The results of the study suggest that in the new social reality, the processes of differentiation and hierarchization of the social status of students continue, and the intensity of these processes is associated with territorial and regional characteristics, with the willingness of graduates to continue their professional career in the specialty obtained at the university or to find a niche in the employment market that provides increasing material needs and a decent standard of living.

Further research will focus on the impact of social, regional and cultural inequalities on the realization of the life aspirations of young people, as well as on the social consequences of the processes of digitalization, the introduction of information technologies on the level and quality of life of young people.

Key words: stratification differences; life chances; precarization; labor market; employment; career; career growth.

Введение. Актуальность изучения влияния социоструктурных различий студенческой молодежи на выбор и шансы построения успешной профессиональной карьеры связана с тем, что в период вхождения во взрослую жизнь после получения диплома о высшем образовании молодые специалисты сталкиваются с противоречиями, связанными с отсутствием гарантированной системы трудоустройства на должности с достойной для молодого специалиста заработной платой, узким спектром социальных гарантий для молодой семьи, достаточно низким статусом инженерной профессии в обществе, недоверием к молодым инженерам на рынке труда. Кроме этого, неустойчивость социального статуса студенческой молодежи заставляет ее осознать смысл целей жизнедеятельности, оценить доступность экономических и профессиональных ресурсов, культурных благ, а также взвесить свои возможности и шансы по реализации предпочтительных жизненных стратегий. Весь этот комплекс проблем по-разному решается в каждой из многочисленных студенческих групп и слоев, различающихся социальным происхождением и территорией проживания, этнической и гендерной принадлежностью, престижностью избранной профессии, поэтому имеющих разные возможности в достижении карьерных устремлений.
По данным социологических исследований, для современной студенческой молодежи на первый план выходит беспокойство за будущий социальный статус и карьеру, так как молодые люди не всегда видят социальные гарантии и возможности реализовать свои намерения. Эту тревогу разделяет и население страны. По данным ВЦИОМ, 47\% опрошенных в 2017 г. считали, что у молодых людей становится все меньше шансов на получение работы по специальности [10].

Статистические данные показывают, что до 40\% выпускников технических факультетов вузов ежегодно трудоустраиваются не по той специальности, которую приобрели в вузе, уходят в торговый бизнес, а не менее $2 \%$ (примерно 2500 человек) уезжают работать за рубеж [6]. Но и среди тех, кто трудоустраивается по специальности на российских предприятиях, в последующие 1-3 года в среднем $20 \%$ вынуждены пройти курсы повышения квалификации и в среднем $10 \%$ переподготовку по другой специальности [2].

Существенное влияние на карьерные возможности выпускников вузов оказывают внешние факторы социальной среды, связанные с интенсивными процессами информатизации, глобализации, углубляющимся состоянием неопределенности и эскалацией риска как следствия социальных изменений, 
противоречиями между социально-возрастными группами в сфере профессиональной деятельности.

Новая социальная реальность как пространство реализации жизненных шансов молодежи. Состояние современного российского общества и его динамику описывают разными определениями: изменяющееся, трансформирующееся, пореформенное, постсоветское. В статье будет использовано понятие «новая социальная реальность». Во всех этих определениях есть существенная составляющая: трансформационные процессы отличаются динамичным характером и разноплановым влиянием на разные слои населения, порождают явления и процессы, которые не только не соответствуют их экспектациям, но к которым никто не стремился и которых никто не хотел [7]. По мнению Ю.А. Зубок, социальный слой молодежи, находящийся в состоянии становления, взросления, обретения субъектности, наиболее остро испытывает последствия состояния неопределенности и рисков [4].

Проблемы, связанные с неопределенностью, нестабильностью на рынке труда, прекаризацией трудовых отношений, ростом новых неравенств, ведут к смене прежних образцов профессиональных карьер, актуализируют аспекты взаимовлияния социального и индивидуального контекстов развития различных типов карьеры. Карьерный рост индивида фокусирует взаимосвязь микро- и макроуровней условий протекания социальных процессов, в которых индивид создает свою карьеру как опыт освоения трансформирующейся сферы занятости - выстраивания связей, мотивации, адаптации, реагирования на социальные изменения. Можно согласиться с мнением И. П. Петровой, которая обращает внимание на то, что концептуализация карьеры исходит из принятого в целом широкого понимания ее как последовательности опытов занятости в рамках жизненного пути с точки зрения отношений индивида и общества [9]. При этом необходимо подчеркнуть, что становление новой социальной реальности отражается на изменении институциональных основ функционирования системы высшего профессионального образования, в которой интенсивно протекает процесс профессиональной социализации молодежи [7].

Для идентификации тенденций становления новой социальной реальности в социологической мысли своевременным является обращение к естественнонаучным теориям, посвященным описанию состояния неопределенности и хаоса, к законам энтропии и введение в научный оборот понятия социальной энтропии [7]. В частности, делается вывод о том, что мерой необратимого (в ряде случаев) и хаотического рассеяния действий человека выступает социальная энтропия. Неупорядоченное рассеивание социальных действий человека и их последствий неизбежно сопровождается становлением обновленной социальной реальности [7]. На макроуровне функционирования новой социальной реальности выделены два существенных противоречия - культурное отставание и управленческое отставание [7].

Как уже подчеркивалось, новая социальная реальность отличается интенсивными процессами цифровизации. Данный аспект важно выделить особо, поскольку построение жизненной карьеры и жизненные шансы молодежи во многом связаны с изменениями, которые претерпевает рынок труда в новых условиях, поскольку изменяется режим работы, система страхования, требования к квалификации работников. Главное отличие: появляются платформы - структурированное виртуальное пространство, которое фактически создает параллельный рынок труда, отличающийся невероятной гибкостью как в плане контрактных обязательств, так и в плане рабочего времени. В результате снижается потребность в постоянных работниках, что отражается на уровне заработной платы в сферах традиционной занятости [7], появляются иные формы социально-трудовых отношений между работодателем и работником, к которым должна быть готова молодежь, вливающаяся в рынок труда. Не отрицая достоинств и преимуществ новой организации производства с применением платформ, нельзя не учитывать социальные аспекты занятости, с которыми необходимо знакомить студенческую молодежь для формирования у них представлений о реальных процессах и готовности выполнять профессиональные трудовые функции в новых ус- 
ловиях. На некоторые проблемы обратили внимание ученые федерального научно-исследовательского социологического центра РАН. Это, в первую очередь, перекладывание традиционных обязанностей работодателей по созданию безопасных и здоровых условий труда на самих работников, изоляция работника и его неучастие в неформальных социальных коммуникациях, утрата мобильными работниками таких социальных навыков, как способность к коллективной работе и толерантность, интенсификация стрессов в социально-психологическом самочувствии [7].

Жизненные шансы карьерного роста молодежи и новые дифференцирующие различия. Как уже подчеркивалось, период студенческой жизни молодежи связан c ее идентификацией не только в качестве объекта воздействия, но в большей степени в качестве самостоятельного субъекта собственной жизнедеятельности и выбора стратегий карьерного роста. Всестороннее обоснование признаков активности, инициативы, ответственности молодежи в процессе построения жизненной стратегии дано в работах К. Абульхановой-Славской. Автор акцентировала внимание на деятельностном аспекте личности молодого человека как субъекте собственной жизни и разработчике стратегии жизни, который обязан объединить индивидуальные возможности, обусловленные статусными, возрастными параметрами, собственные притязания и требования внешней среды [1]. В дополнение к этому Ю.А. Зубок в качестве основополагающего критерия выделила способность к долгосрочному целеполаганию [3]. Иными словами, целесообразно подчеркнуть растущую роль индивидуальных факторов, формирующих многообразие моделей карьерного роста и профессионального развития, имеющих не только линейную направленность. На основе анализа реальных процессов в молодежной сфере занятости на теоретическом уровне стали разрабатываться концепции карьеры различного содержания, опирающиеся на различные исследовательские перспективы: трудовые отношения, гибкая занятость, трудовая мотивация, социальный капитал, прекаризация. Они получили названия: «новая карьера», «безграничная карьера», «традиционная ка- рьера», «устойчивая карьера», «интеллектуальная карьера» [9]. Подобное разнообразие концепций карьеры отражает проблематику изменившихся условий труда в новой социальной реальности, что влечет за собой внимание к меняющимся институтам и структурам рынка труда и занятости, важность переосмысления технологий профориентации в молодежной среде и создания условий для профессионального развития молодежи.

Системный подход к карьерному росту молодежи можно рассматривать и с позиции жизненных шансов. Уточним, под термином «шанс» понимается вероятная возможность осуществления чего-нибудь [8]. Жизненные шансы - это планы, самопрогноз, ценности, жизненные ориентации, сформированные в менталитете молодежи. Жизненные шансы рационально настроенная студенческая молодежь чаще всего связывает с ориентацией на карьерный рост в профессиональной сфеpe, с повышением по должностной лестнице и совершенствованием профессиональных навыков, что должно сопровождаться увеличением размера месячного дохода. Жизненные шансы являются частью многопланового процесса жизнедеятельности и предполагают наличие целей жизни и средств для их реализации как результата собственного выбора молодых людей среди возможных вариантов. Эта картина возможных вариантов уже формируется в процессе выбора специальности при поступлении в вуз, который связывается с перспективой карьерного роста, хорошей заработной платой, легким трудоустройством из-за высокого спроса на специалистов данного профиля, возможностью творческой самореализации, высоким общественным престижем специальности.

Стоит заметить, что осуществление жизненных планов молодежью значительно различается в стабильном обществе и в ситуации общественных трансформаций. П. Штомпка считает, что социальные изменения есть процесс, влияющий на изменение структуры системы, то есть четырех сетей связей между элементами: взаимодействиями (интеракциями), интересами, нормами и идеями [13]. В российском обществе социальных трансформаций наблюдается интенсивная динамика социальной структуры и институтов, появилось больше оснований для иерархизации 
и дифференциации социальных страт, в том числе и в молодежной среде [10]. Учитывая внимание к пространственному развитию регионов и повышению роли вузов в социально-экономическом развитии территорий, можно согласиться с выводами о том, что российские регионы и территории имеют различия, которые являются объективными причинами дифференциации стратегий занятости молодежи: это географические, экономические, этнокультурные, национальные особенности, статус традиционных видов деятельности занятий. К субъективным причинам дифференциации стратегий занятости относят сознательный выбор молодежью специальности, готовность к непрерывному повышению квалификации, горизонтальную профессиональную мобильность [6]. В современных условиях появились новые, свойственные обществу цифровизации и глобализации критерии социальных различий: личный профессионально-квалификационный потенциал и лидерские компетенции молодежи, стартовые возможности из разных, особенно низкодоходных, социальных слоев, социокультурные барьеры, уровень удовлетворенности жизнью, психическое здоровье, цифровое неравенство, вызванное в числе прочего прекаризацией труда. Существенным дифференцирующим фактором успешной карьеры по полученной специальности становится разочарование в своей специальности - отсутствие перспективы, неинтересное содержание и низкая оплата труда, отсутствие спроса на специалистов. На неопределенность карьерной перспективы жалуются, прежде всего, молодые специалисты, занятые в сфере разработки полезных ископаемых (42,9\% из числа разочаровавшихся в своей профессии среди освоивших в вузе данную специализацию), обслуживанием морской техники (50\%). На низкую оплату труда из категории «разочаровавшихся» в специальности жалуются занятые в сфере технологии производственных продуктов (50\%), электронной техники, радиотехники, связи (50\%), электротехники (37,5\%) [2].

В студенческой среде специфическим образом дает о себе знать цифровое неравенство как порождение цифровизации всех сфер жизнедеятельности, в том числе образования. Студенты-первокурсники, посту- пившие из разных территорий - сельских и городских поселений, обладают разными навыками пользования информационно-коммуникативными технологиями, что может быть новой формой социальной дифференциации. Важным является предыдущий опыт работы в цифровом пространстве: те, кто был включен в систему довузовской подготовки, например, участвовал в многопрофильной олимпиаде школьников «Звезда» по информатике, безусловно, занимают более высокую позицию в иерархии умений использовать цифровые технологии в процессе получения профессии.

Ю.А. Зубок считает, что в отличие от предыдущих нынешнее поколение живет со сложившимися беспокойством и ожиданием нестабильного трудового пути, более длинного перехода к гарантированной занятости и, как следствие, опасением планирования в отношении работы или семейной жизни на долгосрочную перспективу, поэтому планы имеют краткосрочную перспективу [4]. По результатам авторских социологических исследований выявлено, что смысложизненные ценности молодежи в сфере труда выглядят следующим образом: заработать (48,7\%), ощутить собственную полезность (28,1\%), проявить творчество (7,7\%), трудиться вынужденно, по необходимости (6,7\%), трудиться в силу внутренней потребности в труде $(6,5 \%)$, ради общения (2,1\%) [4].

Поскольку реализация жизненных планов молодежи связана с состоянием рынка труда и занятости, уточним процессы, которые протекают в этом базовом социально-экономическом институте. По мнению Ж. Т. Тощенко, динамика институциональных изменений обусловила появление нестандартной, неформальной, неустойчивой занятости, нетипичных трудовых отношений. Он особо выделил прекарную занятость с ее специфическими особенностями:

а) численность работников, для которых характерно негарантированное социальноправовое положение;

б) специфические формы и условия организации трудового процесса;

в) произвольная оплата труда или ее эрзацы;

г) полное или частичное отсутствие социальных гарантий; 
д) отстраненность от принятия решений в своей организации. Сюда отнесено социально-психологическое восприятие своего социального положения, когда работники не видят удовлетворяющих их перспектив гражданской и личной (приватной) жизни [10].

Также Ж. Т. Тощенко полагает, что группы молодежи, которые стремятся к определенности и ясности в реализации своего профессионального признания, часто попадают в ситуацию социального исключения, которая имеет все признаки прекаризации их положения [11]. С дискриминацией по месту работы по возрастному признаку сталкивались $33 \%$ работающей молодежи. Это проявляется в занижении оплаты труда, с чем встречались $23,5 \%$ опрошенных, торможение профессионального роста - 6,9\%, искусственное торможение карьеры - 5,7\%, преднамеренное удерживание на непрестижной работе $4,3 \%$ работающей молодежи [2].

Учитывая, что фундаментальные основы профессионального потенциала студентов как залог успешного построения жизненной карьеры закладываются в университетах, необходимо последовательно расширять социально-образовательные технологии, обеспечивающие практико-ориентированную подготовку обучающихся. По экспертной оценке опрошенных руководителей вузов, качество подготовки выпускников позволяет им успешно реализовать себя в профессии примерно в $60 \%$ случаев, в $40 \%$ случаев это не удается из-за отсутствия необходимого спроса на специалистов со стороны предприятий, учреждений [2]. Положительный эффект дают следующие мероприятия: заключение долгосрочных договоров вузов с предприятиями на подготовку специалистов, целевая подготовка и целевое обучение, оплата обучения или выплата стипендии, информирование о перспективах развития предприятия или отрасли, Дни открытых дверей, экскурсии. Отдельного внимания требуют вопросы развития и построения карьеры молодыми учеными, которые планируют работать в высшей школе, получения жилищных сертификатов, развития сетевой аспирантуры.

Заключение. Изучение жизненных шансов как возможности успешного карьерного роста в профессиональной сфере определя- ется личностными устремлениями, влиянием дифференцирующих факторов положения молодежи в социальной структуре общества, готовностью субъектов рынка и занятости обеспечить условия для карьерного роста молодого пополнения. Теоретическое осмысление карьеры как пересечение взаимодействия индивида и социального контекста, структуры и действия, глубоких макроэкономических сдвигов и индивидуального поведения дает системное представление о жизненных шансах карьерного роста молодежи в новой социальной реальности.

Изменяющаяся социальная реальность, состояние неопределенности и риска, противоречия между социально-возрастными группами, социальные аспекты глобализации и цифровизации переориентируют молодежь с построения долгосрочных целей карьерного роста на решение краткосрочных задач, связанных с материальным обеспечением и поиском работы для творческой самореализации.

При формировании профессиональных предпочтений молодых специалистов и в целях их закрепления в профессиональной среде необходимо учитывать новые социоструктурные критерии дифференциации студенческой молодежи, влияющие на возможности гарантированного трудоустройства и успешного карьерного роста: цифровое неравенство, личностные ресурсы, территориальное расположение вуза.

\section{Литература}

1. Абульханова-Славская К.А. Стратегия жизни. - М.: Мысль, 1991.

2. Горшков М.К., Шереги Ф.Э. Молодежь России в зеркале социологии. К итогам многолетних исследований: монография / М.К. Горшков, Ф.Э. Шереги. - М.: ФНИСЦ PAH, 2020. - 688 c. - DOI: 10.19181/ monogr.978-5-89697-325-6.2020.

3. Зубок Ю.А., Чупров В.И. Самоорганизация в проявлениях молодежного экстремизма // Социологические исследования, 2009. - №1. - С. 73-79.

4. Зубок Ю.А., Чупров В.И. Жизненные стратегии молодежи: реализация ожиданий и социальные настроения [Электронный ресурс] // Мониторинг общественного мнения: экономические и социальные пе- 
ремены. - 2020. - №3. - С. 13-41. Режим доступа: https://doi.org/10.14515/ monitoring.2020.3.1602.

5. Индикаторы образования: 2018. Министерство науки и высшего образования РФ, Росстат, Высшая школа экономики. - М.: 2018. - C. 98.

6. Косач Г.Е. Дифференциация стратегий занятости молодежи в российских регионах: объективные и субъективные факторы // Вестник ЮРГТУ (НПИ). — 2020. — №5. C. 91-97.

7. Новая социальная реальность: системообразующие факторы, безопасность и перспективы развития. Россия в техносоциальном пространстве (коллективная монография). - М.; СПб.: Нестор-История, 2020. $208 \mathrm{c}$.

8. Ожегов С.И. Словарь русского языка: ок. 57 слов / Под ред. чл.-корр. АН ССР Н. Ю. Шведовой. - 18-е изд., стереотип. М.: Рус. яз., 1986. — 797 с.

9. Попова И.П. Исследование карьеры: ресурсы междисциплинарности в социологической перспективе // Социологические исследования. - 2020. - Т. 46. — №12. С. $18-30$.

10. Сорокин П.А. Социальная стратификация и мобильность // Человек. Цивилизация. Общество / Общ. ред., сост. и предисл. Ю. Согомонов: Пер. с англ. - М.: Политиздат, 1992.

11. Тощченко Ж. Т. Прекариат: от протокласса к новому классу. Монография / Ж. Т. Тощенко. Институт социологии ФНИСЦ РАН, РГГУ. - М.: Наука, 2018. - 350 с.

12. Тощенко Ж. Т. Прекарная занятость феномент современной экономики // Социологические исследования. - 2020. - №8. C. 3-13.

13. Штомпка П. Социология. Анализ современного общества: Пер. с польск. С.М. Червонной. — М.: Логос, 2005. — 664 c.

\section{References}

1. Abul'hanova-Slavskaja K.A. Strategija zhizni [Strategy of life]. - Moscow: Mysl', 1991.

2. Gorshkov M.K., Sheregi F. Je. Molodezh' Rossii v zerkale sociologii. K itogam mnogoletnih issledovanij: monografija [Youth of Russia in the mirror of sociology. The results of years of research: monograph] / M.K. Gorshkov, F. Je. Sheregi. - Moscow: FNISC RAN, 2020. - 688 p. - DOI: 10.19181/ monogr.978-5-89697-325-6.2020.

3. Zubok Ju. A., Chuprov V.I. Samoorganizacija $\mathrm{v}$ projavlenijah molodezhnogo jekstremizma [Self-organization in the manifestations of youth extremism] // Sociologicheskie issledovanija [Sociological research], 2009. №1. - Pp. 73-79.

4.ZubokJu.A., Chuprov V.I.Zhiznennyestrategii molodezhi: realizacija ozhidanij i social'nye nastroenija [Life strategies of youth: realization of expectations and social moods] [Jelektronnyj resurs] // Monitoring obshhestvennogo mnenija: jekonomicheskie i social'nye peremeny [Monitoring public opinion: economic and social changes]. 2020. — №3. — Pp. 13-41. — URL: https://doi. org/10.14515/monitoring.2020.3.1602.

5. Indikatory obrazovanija: 2018. Ministerstvo nauki i vysshego obrazovanija RF, Rosstat, Vysshaja shkola jekonomiki [Education indicators: 2018. Ministry of Science and Higher Education of the Russian Federation, Rosstat, Higher School of Economics]. - Moscow: 2018. - P. 98.

6. Kosach G. E. Differenciacija strategij zanjatosti molodezhi v rossijskih regionah: obektivnye $i$ subektivnye faktory [Differentiation of youth employment strategies in Russian regions: objective and subjective factors] // Vestnik JuRGTU (NPI). — 2020. — №5. - Pp. 91-97.

7. Novaja social'naja real'nost': sistemoobrazujushhie faktory, bezopasnost' i perspektivy razvitija. Rossija $v$ tehnosocial'nom prostranstve (kollektivnaja monografija) [The new social reality: system-forming factors, security and development prospects. Russia in the technosocial space (collective monograph)]. Moscow; Saint-Petersburg: Nestor-Istorija, 2020. - 208 p.

8. Ozhegov S.I. Slovar' russkogo jazyka: ok. 57 slov [Dictionary of the Russian language: about 57 words] / In chl.-korr. AN SSR N. Ju. Shvedova (eds.). - 18-e izd., stereotip. - Moscow: Rus. jaz., 1986. - 797 p.

9. Popova I.P. Issledovanie kar'ery: resursy mezhdisciplinarnosti $\mathrm{V}$ sociologicheskoj perspektive [Career research: resources of interdisciplinarity in a sociological perspective] // Sociologicheskie issledovanija [Sociological researches]. — 2020. — Vol. 46. — №12. — Pp. 18-30. 
10. Sorokin P.A. Social'naja stratifikacija i mobil'nost' [Social stratification and mobility]// Chelovek. Civilizacija. Obshhestvo [Human. Civilization. Society] / In Ju. Sogomonov (eds.): Per. s angl. - Moscow: Politizdat, 1992.

11. Toshhenko Zh. T. Prekariat: ot protoklassa k novomu klassu. Monografija [Prekariat: from the proto-class to the new class. Monograph] / Zh. T. Toshhenko. Institut sociologii FNISC RAN, RGGU. - Moscow: Nauka, 2018. - 350p.
12. Toshhenko Zh. T. Prekarnaja zanjatost' - fenoment sovremennoj jekonomiki [Prekarnaya employment - a phenomenon of modern economics] // Sociologicheskie issledovanija [Sociological researches]. — 2020. №8. - Pp. 3-13.

13. Shtompka P. Sociologija. Analiz sovremennogo obshhestva: Per. s pol'sk. S.M. Chervonnoj [Analysis of modern society]. - Moscow: Logos, 2005. - 664 p.

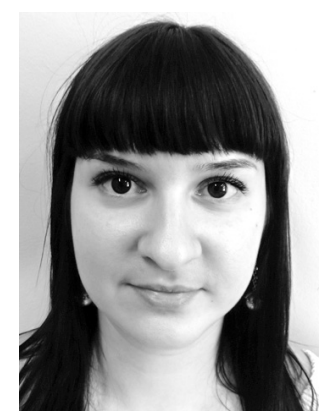

Иваненко Наталия Сергеевна - кандидат социологических наук, доцент кафедры «Социальные и гуманитарные науки» Южно-Российского государственного политехнического университета (НПИ) имени М.И. Платова. Сфера научных интересов - социология молодежи, процессы дифференциации в молодежной среде, социальная помощь и социальная поддержка молодежи, деловые коммуникации в сфере бизнеса и предпринимательства.

Ivanenko Natalia Sergeevna - Candidate of Sociological Sciences, Associate Professor, Department of Social Sciences and Humanities, Platov South Russian State Polytechnic University (NPI). Research interests - sociology of youth, processes of differentiation among youth, social assistance and social support for youth, business communications in the field of business and entrepreneurship.

346428 , г. Новочеркасск, ул. Просвещения, 132

132 Prosveshcheniya st., 346428, Novocherkassk, Russia

E-mail: 79043483051@yandex.ru 